\title{
The Gender of Colorism: Understanding the Intersection of Skin Tone and Gender Inequality
}

\author{
Robert L. Reece ${ }^{1}$
}

Received: 19 July 2019 / Revised: 24 February 2020 / Accepted: 28 February 2020 / Published online: 11 March 2020

(C) Springer Nature Switzerland AG 2020

\begin{abstract}
Although researchers have made great strides in understanding colorism and skin tone stratification in the USA, important connections are still outstanding. One of these connections lies at the intersection of skin tone and gender stratification among black Americans, a place where researchers have certainly visited but work remains to be done. This manuscript builds on previous work to examine how gender and skin tone combine to influence black Americans' social outcomes. To that end, I leverage data from the National Study of Adolescent to Adult Health (Add Health) and regression analysis to test the effect of skin tone and gender on black Americans' individual incomes. My results suggest a three-tiered hierarchy of income stratification. Light-skinned men sit atop this hierarchy with higher incomes than other black Americans after controlling for other relevant factors. Dark-skinned people suffer at the bottom of this hierarchy with lower incomes than the other gender and skin tone combinations (medium-skinned men, light-skinned women, and medium-skinned women).
\end{abstract}

Keywords Gender $\cdot$ Skin tone $\cdot$ Colorism $\cdot$ Race/ethnicity $\cdot$ Income

\section{Introduction}

Over the past two decades, the number of color discrimination claims filed with the Equal Employment Opportunity Commission (EEOC) has quadrupled even though the number of overall claims has remained relatively consistent. This signals a spike in public awareness and acknowledgement of color or skin tone discrimination. Concurrently, scholarship dedicated to color has increased dramatically, and skin tone has become an almost standard inclusion in social science surveys. As a result, our knowledge of the extent of color stratification has improved significantly in recent years, and, so far, it seems ever-present, permeating almost every aspect of society.

However, our knowledge continues to expand in important ways. As we continue to establish that color stratification is a constant throughout American society, we must also develop our understanding of how it works. Although we have made recent strides in developing theories to explain the

Robert L. Reece

Robert.L.Reece@gmail.com

1 Department of Sociology, The University of Texas at Austin, $305 \mathrm{E}$ 23rd St, A1700, RLP 3.306, Austin, TX 78712-1086, USA mechanisms (such as Goldsmith et al. 2007; Hargrove 2018a, b; Finkeldey and Demuth 2019; Louie 2019; Monk 2015; Painter et al. 2015; Reece 2018a, b, c), we still have ways to go. One vital step is to examine how different groups are affected by color stratification. For example, we have produced a robust amount of research that demonstrates the nearubiquity of color stratification among black Americans, but moving forward to truly grasp the contours of the phenomenon, we have to see black Americans as more than a homogenous group and explore whether colorism affects all black Americans equally.

The most straightforward way to launch a research platform that investigates how color intersects with other social locations is through an analysis of gender, where full comparisons of the effects of color between men and women are limited. Although income and wages are among the most studied outcomes in color research with ten studies (Goldsmith et al. 2006; Goldsmith et al. 2007; Hersch 2006; Hunter 1998; Hunter 2002; Keith and Herring 1991; Kreisman and Rangel 2015; Monk 2014; Robst et al. 2011; Sweet et al. 2007), all consistently showing considerable advantages for lighter skinned black Americans, they lack a thorough gender analysis. Some of these elected to build a theoretical framework that focused on one gender (i.e., Hunter 1998, 2002), others focused on a single gender to 
circumvent data and methodological concerns (i.e., Goldsmith et al. 2006; Goldsmith et al. 2007; Kreisman and Rangel 2015), and others offer side-by-side gender comparisons but not necessarily intersectional comparisons (i.e., Hersch 2006; Keith and Herring 1991). I seek to build on this groundwork by bringing an intersectional lens to an analysis of color and gender, where I will not only compare the effect of color between men and women but also compare the combined effect of gender and color. This will show whether colorism remains consistent across gender, provide insight into whether gender or color is more important to the life outcomes of black Americans, and, because it is impossible to isolate real world experiences to a single social characteristic, this will give us a better view into how black Americans experience life. Ultimately, my results reveal a complex relationship between gender and color. Both lighter skinned men and lighter skinned women earned more than their darker skinned counterparts. However, when comparing combinations of gender and color light-skinned men seem to stand apart from everyone else, suggesting they benefit from a combination of favorable gender status and favorable color status. Conversely, dark-skinned people seem to suffer the effects of subordinate color status, while there seems to be no significant difference between the individual incomes of light-skinned women, medium-skinned women, and medium-skinned men.

\section{Colorism, Gender, and Intersectionality}

Colorism is the process by which people of color with phenotypic features more closely associated with whiteness - such as lighter eyes, thinner noses and lips, straighter hair, and particularly lighter skin tones-are offered social and economic advantages relative to their counterparts with more "ethnic" phenotypic features - darker eyes, thicker noses and lips, curly hair, and darker skin. The near ubiquity of colorism has been well researched, particularly among black Americans, although the phenomenon has been documented in almost every country in the world (Hunter 2005). In addition to wages and income, relative to darker skinned black Americans, lighter skinned black Americans have been shown to enjoy better mental and physical health (Diette et al. 2015; Hargrove 2018a, b; Laidley et al. 2019; Louie 2019; Monk 2015; Perreira et al. 2018), experience fewer negative encounters with the criminal justice system (Blair et al. 2004; Finkeldey and Demuth 2019; Monk 2018; Viglione et al. 2011), are punished less and less harshly in schools (Hannon et al. 2013), and are viewed as more attractive (Reece 2016). Moreover, the pernicious effects of colorism have remained persistent since before emancipation, operating through a system of light skin preference and long-term accumulated economic advantage (Bodenhorn 2002, 2006, 2011; Bodenhorn
2007; Green and Hamilton 2013; Gullickson 2010; Reece 2018a, b; Saperstein and Gullickson 2013).

However, our ever-increasing knowledge of the workings of colorism has not yielded a robust examination of the possible intersectional effects. Particularly, although some scholars suggest skin color may be gendered (Hunter 1998, 2002), our empirical understanding of how colorism may present differently for men and women remains limited. We have yet to scrutinize whether there are differences in the overall effect of colorism for men and women and, ultimately, which is more important to shaping the lives of black Americans, and how their lives may hinge on complex interactions between the two social locations - color and gender.

Although "intersectionality" has become a popular term in social science research and in public discourse, it is arguably overused and misunderstood, which limits its usefulness in scholarly contexts. Kimberle Crenshaw $(1989,1991)$ coined the term to explain how social locations combined to produce unique ways of interacting with the social world. Rather than examining social phenomena in isolation, such as only race or only gender or only color, Crenshaw encouraged scholars to consider them in combination, with particular attention to how they produced new and different social locations rather than a collection of stacked categories. That means an intersectional approach to understanding color and gender would examine not simply whether color matters for men and women but how color and gender may merge to shape social outcomes. Essentially, it is the difference in "dark skinned + woman" versus "darkskinnedwoman," where the former indicates simply adding social categories and the latter represents how categories are transformed by one another. This offers deeper insight into the complexity of the social forces that may shape people's lives and thus provides better leverage for staging effective interventions.

\section{Color and Income}

I will focus my attention on the effect of color and gender on individual income for black Americans. I chose income because it is an intuitive and important social outcome, and it is among the most studied outcomes examined in relation to color, but it lacks a thorough intersectional gendered analysis.

I found ten studies from 1991 to 2015 that connect color to income. Each one offers unique insight into the workings of colorism but they take a few different approaches to the analysis of gender. Two studies used samples of the entire black American population and did not separate their analyses by gender (Monk 2014; Sweet et al. 2007). The remaining studies include gendered elements that I plan to build on with this manuscript.

Hunter $(1998,2002)$ focuses on building a framework for how black women experience colorism; therefore, she limits 
her analyses to black women. Conversely, Goldsmith et al. (2006, 2007) and Kreisman and Rangel (2015) limit their analyses to black men. While they are not specifically building a framework for black men in the way Hunter tries to do for black women, they present methodological concerns that lead them to narrow their samples to men. Particularly, because they are making comparisons between black and white Americans, are wary of comparing the wages of black and white women. They sought to "[avoid] the modeling of female labor force decisions, which are often substantively different for black and white women" (Kreisman and Rangel 2015, p. 6). Robst et al. (2011) examine players in the National Basketball Association (NBA) so their analysis is necessarily limited to men.

The remaining two studies (Hersch 2006; Keith and Herring 1991) offer side-by-side comparisons of men and women, which offer important insights into the gender differences in skin color stratification. They both suggest the effects of colorism on individual income may be stronger for men than for women although both lighter skinned men and women are advantaged relative to their darker counterparts.

See Table 1 for a breakdown of these studies, including descriptions of the gendered composition and dates of their samples and whether they included a gendered analysis.

I plan to build on the previous analyses in a few ways. Because I am not conducting interracial comparisons, I am not forced to limit my sample to men. Instead, I will conduct in-depth gender analyses to provide a fuller picture of how gender and color may intersect. In addition to side-by-side analyses similar to Hersch (2006) and Keith and Herring (1991) that compare the effect of color between men and women, I will examine the combined effect of color and gender on income. Specifically, I will compare light-skinned men to light-skinned women to-medium skinned men to mediumskinned women to dark-skinned women to dark-skinned men. Although previous research shows both men and women suffer the effects of colorism, we do not understand what that means substantively. Because people cannot isolate their gender from their color in real-world situations it is important to understand how they work in combination if we seek to understand color at all. For example, lighter skinned women earn more than darker skinned women and lighter skinned men earn more than darker skinned men, and from that, we learn colorism affects each gender. But what can we glean from comparing lighter skinned women to darker skinned men. Perhaps if lighter skinned women earn more in that scenario, it is a signal that color trumps gender in shaping the lives of black Americans. Conversely, if darker skinned men earn more in that scenario, it may be a signal that gender is more important than color in influencing the life chances of black Americans. Either way we may find that favorable color status can be tempered by subordinate gender status and/or dominant gender status can be tempered by unfavorable color status. The answer is surely more complex than this simple example, but my analyses will help us begin to recognize these complexities and gain a more complete understanding of how black Americans experience the world.

Moreover, previous studies of gender and color, i.e., Hersch (2006) and Keith and Herring (1991), used data from the early 1980s and mid-1990s that was timely when they conducted their research, but more recent data is available that I plan to leverage for my analyses. But this is more than a general data update. A number of sources point to shifts in the racial and color landscape that may lead to results that differ significantly from those of studies that used older data. Color stratification may be again coming to the fore of American public discourse. As I opened this manuscript with, color claims filed with the EEOC have increased dramatically since the mid-2000s, and filmmakers have offered a public a steady stream of documentaries examining colorism since around the same time in the mid-2000s. Moreover, studies suggest the racial and political attitudes of darker and lighter skinned black Americans may have diverged over this same period, shifting from a so-called "skin color paradox" (as outlined by Hochschild and Weaver 2007) where black Americans exhibited no color differences in attitudes to sharp
Table 1 Studies of color and income/wages

\begin{tabular}{llll}
\hline Study & Sample gender & Sample year & Gender analysis \\
\hline Keith and Herring 1991 & Men and women & $1979-1980$ & Compares men and women \\
Hunter 1998 & Women only & $1979-1980$ & No comparison group \\
Hunter 2002 & Women only & $1979-1980$ & No comparison group \\
Hersch 2006 & Men and women & $1979-1980 ; 1992-1994 ;$ & Compares men and women \\
Goldsmith et al. 2006 & Men only & 1992 & No comparison group \\
Goldsmith et al. 2007 & Men only & 1992 & No comparison group \\
Sweet et al. 2007 & Men and women & $2000-2001$ & Does not compare genders \\
Robst et al. 2011 & Men only & $2001-2007$ & No comparison group \\
Monk 2014 & Men and women & $2001-2003$ & Does not compare genders \\
Kreisman and Rangel 2015 & Men only & 2008 & No comparison group \\
\hline
\end{tabular}


differences on a number of issues reflecting their social positions (Hutchings et al. 2016; Wilkinson and Earle 2012). In general, more recent studies suggest darker skinned black Americans are more liberal and less likely to embrace racial stereotypes about black people; whereas lighter skinned black Americans are less supportive of liberal social policies and tend to embrace more racial stereotypes about black people (Hutchings et al. 2016). These attitudinal shifts may coincide with changes in the meaning of blackness as more and more people begin to identify as multiracial on the heels of changes to the 2000 Census that allowed people to select more than one race for the first time, increasing numbers of interracial marriages, and the election of the black multiracial Barack Obama (Mason 2017). Finally, Kreisman and Rangel (2015) find evidence that the color gap may be widening, and Reece (2018a) argues the gap may continue to widen as more opportunities open for black Americans. In combination, these factors underscore the importance of analyzing color and income using more recent data.

\section{Data and Methods}

The data for this study come from the National Study of Adolescent to Adult Health (AddHealth), a nationally representative longitudinal survey that has followed a cohort of adolescents through four waves of data collection since 1994.

My sample includes black people based on their selfidentified race in wave 3 , where the interviewers also recorded skin tone. Where respondents selected multiple races, I included them in the sample if they listed black as the race they most strongly identified with.

My dependent variable is the natural log of individual income in wave 4, which was collected in 2008. I excluded respondents who reported 0 income.

\section{Focal Independent Variable}

My focal independent variable is skin tone, which is a proxy for color. Although color is a complex interplay of skin tone and other physical characteristics, skin tone remains most closely associated with racial categorization (Feliciano 2016). Add Health codes skin tone using an interviewercoded 5-point scale during wave 3 , with " 1 " representing the darkest skin tone and " 5 " representing the lightest skin tone. I reverse coded the variable so " 5 " is the darkest skin tone and " 1 " is the lightest so the variable is a progressive scale of skin darkness. With my later models, I collapsed the ends of the scale for ease of interpretation, to ensure each category had enough cases to make relevant comparisons, and to account for the subjectivity of skin tone ratings (which I discuss in greater detail below). Where the models indicate categorical skin color divisions: light-skinned, medium-skinned, dark- skinned: " 1 " and " 2 " are light-skinned, " 3 " is mediumskinned, and " 4 " and " 5 " are dark-skinned.

A number of scholars have criticized the subjectivity of interviewer-coded skin tone ratings. Systematic analyses have found that when using the Massey-Martin Scale (the scale of skin color from 1 to 10 using a palette of colored hands), white interviewers overate the darkness of black respondents by one compared to how black interviewers rate other black people, which raises additional questions of endogeneity when estimating the effect of color on skin tone where interviewers may rate more affluent people as lighter (Hill 2002a, b; Hannon and DeFina 2014, 2016). As a possible solution, they suggest using a device such as a photospectrometer, which measures the amount of light that reflects off the skin, to measure skin tone. Add Health uses a five-point scale that differs from the Massey-Martin Scale, but I sought to account for the possible effect of interviewer bias on my results. First, I tested for interviewer effects by introducing variables for interviewer race, gender, and education. My results remained consistent, and each of the interviewer variables was non-significant so I ultimately excluded them from the analyses shown here. Second, Hannon and DeFina (2020) suggest that rather than asking interviewers to memorize a fine-grained scale such as the Massey-Martin Scale, interviewers may be more equipped to rate respondents on a simpler scale such as "light," "medium," and "dark." While I cannot control the rating scale of Add Health interviewers, I adopted a version of this reasoning in my analyses by collapsing the five-point scale into a threepoint scale.

I also include a number of other variables as controls to isolate the relationship between skin tone and income: gender, age, education, weekly hours worked, whether the respondent grew up in a two-parent household, mother's education, and father's education. Gender is a dichotomous variable for whether a respondent is a woman. Age is each respondent's age in wave 4. Education is a measure of total years of schooling, such that a high school education is " 12 ," a bachelor's degree is " 16 ," and a master's degree is "18,". Weekly hours worked is the respondent's report of how many hours they typically work in a week. This is important because men typically work more hours per week than women and may partially account for the income disparity between the two groups. Two-parent household and parents' education are designed to measure family background to account for the effect of childhood affluence on future income. Two-parent household is a dichotomous variable for whether a respondent reported having both parents at home during wave 1. Father's and mother's education are coded the same as the respondent's education; if a parent was absent, their education is coded as " 0 " (see Table 2 for descriptive statistics and Table 3 for how the sample breaks down proportionally by gender and skin tone). 
Table 2 Descriptive statistics $(n=2047)$

\begin{tabular}{lll}
\hline Variable & Mean & SD \\
\hline Income & 26,172 & 1328.81 \\
Log (income) & 9.85 & 0.05 \\
Skin tone & 3.71 & 0.06 \\
Woman & 0.51 & - \\
Age & 28.75 & 0.19 \\
Two parent & 0.43 & - \\
Mother's edu & 12.5 & 0.20 \\
Father's edu & 5.91 & 0.25 \\
Edu & 13.60 & 0.15 \\
Weekly hours & 38.81 & 0.69 \\
\hline
\end{tabular}

\section{Analytic Strategy}

I use three series of models to examine the intersection of skin tone and gender and their effect on income. The first models serve as a baseline for my deeper examinations. I estimate one model with my entire sample, including all of my independent variables. Next, I disaggregate my sample by gender and estimate separate models for men and women to test whether the relationship between skin tone and income holds for each group. The second set of models emerged from the first. As I realized gender was only marginally significant, I estimated a series of models with the sample disaggregated by skin tonelight skinned, medium skinned, dark skinned. This revealed whether the relationship between gender and income varied by skin tone. Finally, my third series of models attempts to offer a better understanding of how skin tone and gender work together to shape income. I do this by estimating a series of models that includes dummy variables to represent combinations of gender identity and skin tone. That means I created dummy variables for light-skinned men, medium-skinned men, dark-skinned men, light-skinned women, mediumskinned women, and dark-skinned women. I estimated six individual models, excluding each category in turn as the reference category. Light-skinned men is the reference category in one model, then medium-skinned men, then dark-skinned men, then light-skinned women, then medium-skinned women, and finally dark-skinned women. This allowed me to compare each category to every other category to determine which are significantly different from each other and which are not.

Table 3 Sample proportions by gender and skin tone

\begin{tabular}{lllll}
\hline & All & Men & Women & \\
\hline All & & 0.49 & 0.51 & 1.00 \\
Light skinned & 0.14 & 0.05 & 0.08 & \\
Medium skinned & 0.28 & 0.12 & 0.17 & \\
Dark skinned & 0.58 & 0.31 & 0.27 & \\
& 1.00 & & & 1.00 \\
\hline
\end{tabular}

I used PROC SURVEYREG in the SAS statistical software to apply the appropriate sampling weights to my models.

\section{Results}

My results reveal a complex story about color and gender.

Table 4 offers a series of baseline results. As expected, skin tone was negative and significant for the entire sample, meaning darker skinned black Americans earned less money on average. This is consistent with previous studies of colorism and income. However, the woman variable was only marginally significant, which I sought to investigate in the next series of models. Continuing with the current models, skin tone was negative and significant for both men and women, meaning both darker skinned men and darker skinned women earned less money. However, the skin tone coefficient is larger in the model for men, suggesting men may suffer the impact of color on income more severely than women, but the remaining series of models offers more insight into that possibility.

The marginal significance of gender in my first model prompted me to test whether the relationship between gender and income varied by skin tone (see Table 5 for the results of these models). The woman variable was negative and significant for light-skinned black Americans but non-significant for medium- and dark-skinned black Americans. This means relative to light-skinned men, light-skinned women tend to earn less income, while medium-skinned and darker skinned women do not earn less on average than medium-skinned and darker skinned men respectively. This means the income difference between light-skinned men and light skinned women is likely larger, net of other factors, than the difference between medium- and dark-skinned men and women, but it does not tell us how the six groups ultimately stack up relative to one another. For that, I needed another series of models.

Table 4 OLS estimates of income for black Americans by gender

\begin{tabular}{|c|c|c|c|}
\hline & $\begin{array}{l}\text { All } \\
\beta(\mathrm{SE})\end{array}$ & $\begin{array}{l}\text { Men } \\
\beta(\mathrm{SE})\end{array}$ & $\begin{array}{l}\text { Women } \\
\beta \text { (SE) }\end{array}$ \\
\hline Intercept & $5.75 * * *(0.79)$ & $6.13 * * *(1.11)$ & $5.38 * * *(0.95)$ \\
\hline Skin tone & $-0.09 * *(0.03)$ & $-0.13 *(.05)$ & $-0.06^{*}(0.03)$ \\
\hline Woman & $-0.15^{\dagger}(0.08)$ & - & - \\
\hline Age & $0.05 *(0.02)$ & $0.06 *(0.03)$ & $0.03(0.03)$ \\
\hline Two parents & $-0.11(0.19)$ & $0.22(0.32)$ & $-0.45(0.17)$ \\
\hline Mother's edu & $0.01(0.01)$ & $-0.002(0.02)$ & $0.03(0.01)$ \\
\hline Father's edu & $0.02^{\dagger}(0.01)$ & $0.002(0.02)$ & $0.04 * *(0.01)$ \\
\hline Education & $0.13 * * *(0.02)$ & $0.10 * *(0.03)$ & $0.17 * * *(0.02)$ \\
\hline Weekly hours & $0.03 * * *(0.003)$ & $0.03 * * *(0.005)$ & $0.03 * * *(0.005)$ \\
\hline$n$ & 1715 & 702 & 1013 \\
\hline r-squared & 0.16 & 0.12 & 0.23 \\
\hline
\end{tabular}


Table 5 OLS estimates of income for black Americans by skin tone

\begin{tabular}{lllll}
\hline & $\begin{array}{l}\text { All } \\
\beta(\mathrm{SE})\end{array}$ & $\begin{array}{l}\text { Light skinned } \\
\beta(\mathrm{SE})\end{array}$ & $\begin{array}{l}\text { Medium skinned } \\
\beta(\mathrm{SE})\end{array}$ & $\begin{array}{l}\text { Dark skinned } \\
\beta(\mathrm{SE})\end{array}$ \\
\hline Intercept & $5.75^{* * *}(0.79)$ & $6.00^{* *}(1.45)$ & $4.86^{* *}(1.22)$ & $5.51^{* * *(1.07)}$ \\
Skin tone & $-0.09^{* *}(0.03)$ & - & - & - \\
Woman & $-0.15^{\dagger}(0.08)$ & $-0.34^{*}(0.15)$ & $-0.03(0.16)$ & $-0.15(0.12)$ \\
Age & $0.05^{*}(0.02)$ & $0.07(0.04)$ & $0.06(0.04)^{\dagger}$ & $0.04(0.03)$ \\
Two parents & $-0.11(0.19)$ & $0.43(0.30)$ & $0.02(0.47)$ & $-0.33(0.21)$ \\
Mother's edu & $0.01(0.01)$ & $-0.01(0.02)$ & $0.02(0.03)$ & $0.02(0.01)$ \\
Father's edu & $0.02^{\dagger}(0.01)$ & $-0.03^{\dagger}(0.02)$ & $0.01(0.03)$ & $0.04 * *(0.01)$ \\
Eeducation & $0.13^{* * *}(0.02)$ & $0.11^{* *}(0.03)$ & $0.12^{* *}(0.03)$ & $0.14 * *(0.04)$ \\
Weekly hours & $0.03^{* * *}(0.003)$ & $0.03^{* * *(0.01)}$ & $0.03 * * *(0.004)$ & $0.02 * * *(0.004)$ \\
$n$ & 1715 & 270 & 508 & 937 \\
r-squared & 0.16 & 0.27 & 0.20 & 0.13 \\
\hline
\end{tabular}

$* * * p<0.0001 ; * * p<0.01 ; * p<0.05 ;{ }^{\dagger} p<0.10$
First, Fig. 1 shows mean income by gender and skin tone to provide an idea of the numbers I am comparing with the next regressions. As expected, there appears to be a stepwise decrease in income as skin tone darkens, for both men and women. Notably, however, men earn more than women at each skin tone level, and only light-skinned women earn more than any group of men. Light-skinned women earn slightly more than dark-skinned men. The following models will elaborate on this figure and indicate whether the comparisons are statistically significant.

Table 6 shows six individual models, each using one of the gender-skin tone combinations as the reference category. Taken together, the models seem to reveal a three-tiered structure with light-skinned men standing ahead, dark-skinned women standing behind, and everyone else in the middle.

The first model reveals light-skinned men earn more on average than every other group. With light-skinned men as the reference category, each of the other group variables is negative and significant. The next two models, with medium-skinned men and dark-skinned men as the reference category respectively, begin to reveal how light-skinned men stand above the other groups. In each of these models, the variable for light-skinned men is positive and significant, while the variables for the other categories are non-significant. That affirms that light-skinned men earn more on average than medium- and dark-skinned men, but there appears to be no difference between medium- and dark-skinned men and between medium- and dark-skinned men and women regardless of skin tone.

The following three models use light-skinned women, medium-skinned women, and dark-skinned women, respectively, as the reference category. They offer additional evidence of the advantages of light-skinned men and also reveal the disadvantages of dark-skinned women.

For the models using light-skinned women and mediumskinned women as the reference category, the variable for light-skinned men is positive and significant and the variable for dark-skinned women is negative and significant. That means light-skinned men earn more than-light and mediumskinned women while dark-skinned women earn less than
Fig. 1 Mean income by skin tone and gender

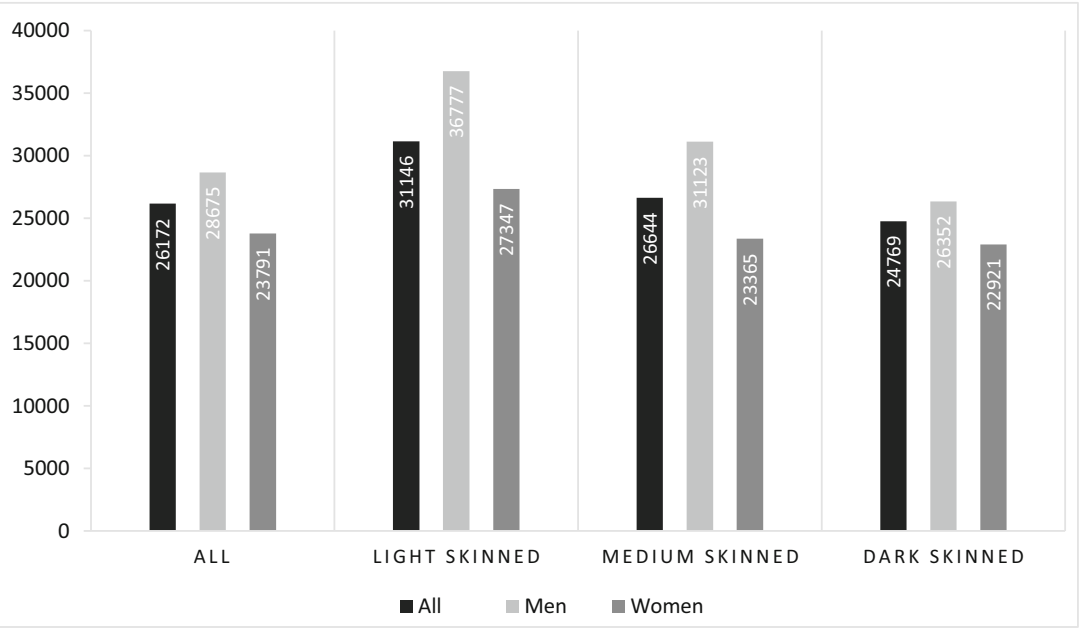


Table 6 OLS estimates of income for black Americans by gender and skin tone

\begin{tabular}{|c|c|c|c|c|c|c|}
\hline Reference group & $\begin{array}{l}\text { Light-skinned } \\
\text { men }\end{array}$ & $\begin{array}{l}\text { Medium-skinned } \\
\text { men }\end{array}$ & $\begin{array}{l}\text { Dark-skinned } \\
\text { men }\end{array}$ & $\begin{array}{l}\text { Light-skinned } \\
\text { women }\end{array}$ & $\begin{array}{l}\text { Medium-skinned } \\
\text { women }\end{array}$ & $\begin{array}{l}\text { Dark-skinned } \\
\text { women }\end{array}$ \\
\hline & $\beta(\mathrm{SE})$ & $\beta(\mathrm{SE})$ & $\beta(\mathrm{SE})$ & $\beta(\mathrm{SE})$ & $\beta(\mathrm{SE})$ & $\beta(\mathrm{SE})$ \\
\hline Intercept & $5.75 * * *(0.80)$ & $5.42 * * *(0.81)$ & $5.36 * * *(0.84)$ & $5.46^{* * *}(0.82)$ & $5.35 * * *(0.82)$ & $5.23 * * *(0.80)$ \\
\hline Light-skinned man & - & $0.36^{* *}(0.17)$ & $0.42 * *(0.14)$ & $0.31 *(0.14)$ & $0.43 * * *(0.11)$ & $0.55 * * *(0.11)$ \\
\hline Medium-skinned man & $-0.37 *(0.17)$ & - & $0.05(0.17)$ & $-0.05(0.19)$ & $0.07(0.16)$ & $0.19(0.15)$ \\
\hline Dark-skinned man & $-0.42 * *(0.13)$ & $-0.07(0.16)$ & - & $-0.11(0.11)$ & $0.01(0.10)$ & $0.13(0.11)$ \\
\hline Light-skinned woman & $-0.33 *(0.14)$ & $0.03(0.18)$ & $0.09(0.11)$ & - & $0.11(0.09)$ & $0.23^{*}(0.11)$ \\
\hline $\begin{array}{l}\text { Medium-skinned } \\
\text { woman }\end{array}$ & $-0.44 * * *(0.10)$ & $-0.09(0.16)$ & $-0.02(0.10)$ & $-0.13(0.09)$ & - & $0.11^{\dagger}(0.06)$ \\
\hline Dark-skinned woman & $-0.56 * * *(0.11)$ & $-0.21(0.15)$ & $-0.14(0.11)$ & $-0.25^{*}(0.11)$ & $-0.13 *(0.06)$ & - \\
\hline \multicolumn{7}{|l|}{ Controls not shown } \\
\hline$n$ & 1720 & 1720 & 1720 & 1720 & 1720 & 1720 \\
\hline r-squared & 0.16 & 0.16 & 0.16 & 0.16 & 0.16 & 0.16 \\
\hline
\end{tabular}

$* * * p<0.0001 ; * * p<0.01 ; * p<0.05 ;{ }^{\dagger} p<0.10$

light- and medium-skinned women. The model with darkskinned women as the reference category builds on this finding. In that model, the variable for light-skinned men is predictably positive and significant, and the variables for lightskinned women and medium-skinned women are also positive and significant. That means dark-skinned women earn less than light-skinned men, as does every other group being analyzed here, but they also earn less than light- and mediumskinned women. Taken together, these three models support the earlier three models that light-skinned men are advantaged relative to every other group and show dark-skinned women are disadvantaged relative to other women while there seems to be no significant difference between light- and mediumskinned women.

I chose one final analysis to help me continue to build a well-rounded picture of the relationship between gender and skin tone. I used the previous regressions to generate predicted values of $\log$ (income). The following tables show the ratio of men's to women's mean predicted income organized by skin tone. This will offer comparisons of each gender-skin tone combination. Each cell in the table shows a ratio, so values above 1 show men earn more, values below 1 show women earn more, while a value of 1 means their incomes are equal. I shaded cells where women's incomes are equal or greater than those of men. To account for differing labor market decisions between men and women, I provide two tables: one for respondents with more than a high school education and one for respondents with a high school or less education.

Table 7 shows ratios for respondents with over a high school education. The "L" shape of the shading suggests that among this segment of respondents, color seems to have a stronger influence on income than gender. Women of each color category earn equal or more than men who are darker than them. Light-skinned women earn more than medium- and dark-skinned men. Medium-skinned women earn more than dark-skinned men. Supporting the premise from the previous analyses that light-skinned men stand in a tier above everyone else, they are the only group of men to earn more than each group of women. Light-skinned women only earn less than light-skinned men. While dark-skinned men and dark-skinned women both earn less than everyone lighter regardless of gender, while their incomes are roughly equal to each other, which reinforces the above findings suggesting dark-skinned people face unique disadvantages.

However, the table of respondents with a high school education or less reveals a different, less complex story. There, men earn more than women regardless of skin tone, suggesting gender supersedes skin tone for that group, which stands in sharp contrast to respondents with more education. But even though men earn more in each cell, the difference between men with darker skin tones and women with lighter skin tones is smaller than the difference between men with darker skin tones and women with darker skin tones. For example, the gap between dark-skinned men and lightskinned women is smaller than the gap between darkskinned men and dark-skinned women. Therefore, while gender appears to be more important, there is still an interactive, buffering effect of skin tone that decreases the gender gap.

Table 7 Ratio of men-to-women's predicted income for respondents over high school edu

\begin{tabular}{c|cccc}
\multicolumn{1}{c}{} & \multicolumn{3}{c}{ WOMEN } \\
\cline { 3 - 5 } \multicolumn{1}{c}{ MEN } & light & medium & dark \\
\cline { 3 - 5 } & light & 1.02 & 1.04 & 1.05 \\
& medium & 0.99 & 1.02 & 1.03 \\
& dark & 0.97 & 0.99 & 1
\end{tabular}


Table 8 Ratio of men-to-women's predicted income for respondents high school edu or less

\begin{tabular}{lllll}
\hline \multirow{4}{*}{} & & \multicolumn{2}{l}{ Women } & \\
\cline { 3 - 5 } & & Light & Medium & Dark \\
\hline \multirow{3}{*}{ Men } & Light & 1.09 & 1.1 & 1.11 \\
& Medium & 1.04 & 1.05 & 1.06 \\
& Dark & 1.03 & 1.04 & 1.05 \\
\hline
\end{tabular}

\section{Discussion/Conclusion}

These results suggest a complex tiered system in regard to the intersection of gender and color. Light-skinned men unambiguously stand at the top of this intersectional hierarchy as they have higher incomes than every other group, in every analysis, even after accounting for a number of other factors. Below, light-skinned men is where the complexity lies. Seems as if there is little difference between light-skinned women, medium-skinned women, and medium-skinned men, even as they are disadvantaged relative to light-skinned men. Sitting at the bottom of the hierarchy are dark-skinned men and women. This points to color as a central organizing feature of black life that trumps gender for some groups, while for others, the combination of the two stands out. Light-skinned men benefit from the dual advantages of favorable skin tone and favorable gender, whereas dark-skinned people cannot overcome the disadvantage of their skin tone even if they also have a favorable gender. Dark skin seems to flatten the gender hierarchy into a puddle of disadvantage while light skin exacerbates the gender hierarchy by offering room for differences to emerge. However, it is also important to acknowledge that the predicted values in Table 8 suggest additional complexities based on education level that warrants a fuller analysis. Lower levels of education seems to provide the opportunity for men to create greater income differences between themselves and women, particularly women of darker skin tones.

The mechanisms that produce color advantage and color preference may also differ by gender such that dark-skinned women may suffer uniquely compared to other women than compared to similarly complexioned men. That idea warrants deeper investigation. For example, a number of studies connect color and attractiveness (Hill 2002a, b; Hunter 2002; Reece 2016; Ryabov 2019). In the most recent, Ryabov (2019) finds attractiveness is more strongly tied to color and status attainment for women than men. Social differences in the value of attractiveness for women relative to men, where attractiveness is a more dominant force in the lives of women, may be an important factor explaining why dark-skinned women are disadvantaged when specifically compared to other women but not when compared to most other men.
Although this study shows the relationship between gender and color is complex, it also points to light skin as a central factor in shaping black social outcomes. Previous research suggests skin tone may be a stronger predictor of black life chances than parents economic status (Keith and Herring 1991), and this paper suggests it may exacerbate gender stratification as light-skinned men appear to be particularly dominant, at least as far as income is concerned. Social scientists and policy makers must reorient themselves to consider color as one of the defining factors in black lives and devote the necessary amount of attention to it. The conventional "big three" of social science - race, gender, and class — cannot continue to dominate our discussions of stratification if studies continue to show that other factors, in this case color, may be more influential. We have to break with tradition and embrace alternate explanations for stratification and perhaps even alternate ways of measuring stratification, which I will address next.

Studies such as this also force us to continue to question the nature of race in the USA, particularly whether our standard system of racial classification with its supposedly closed boundaries, and sharp racial demarcations accurately measure the experiences of black Americans and offer a truthful representation of racial inequality. A study by Goldsmith et al. (2007) suggests the wage gap between light-skinned black Americans and dark-skinned black Americans may be larger than the gap between white Americans and light-skinned black Americans. Moreover, a study by Kreisman and Rangel (2015) suggests that the gap between light- and dark-skinned black Americans may actually be widening. And a study of obesity by Reece (2018a ) suggests light-skinned black Americans suffer an obesity wage penalty more similar to white Americans than their darker skinned counterparts. If light-skinned black men are so different from medium- and dark-skinned black Americans, racial data that does not account for color risks greatly underestimating the disadvantage of darker black Americans and women, especially relative to white people. It is possible that apparent opportunities opening for black Americans actually represent increasing opportunities for lightskinned black Americans who have been able to dramatically increase their social standing while darker black Americans continue to languish and fall further and further behind.

To ignore alternate or additional ways of measuring race is to fail to comprehensively examine the contours of racial stratification. As social scientists, we must refuse to become trapped by tradition, which means we need to constantly interrogate whether we are capturing what we seek to capture using our chosen methods of measurement. It is simply not enough to continue to measure race "the way we have always done it" if those ways mask critical aspects of our society. I hope to join the call to sociologists, race scholars in particular, and social scientists in general, to rethink how we measure race in the USA. 


\section{References}

Blair IV, Judd CM, Chapleau KM. The influence of Afrocentric facial features in criminal sentencing. Psychol Sci. 2004;15(10):674-97.

Bodenhorn $\mathrm{H}$. The mulatto advantage: the biological consequences of complexion in rual antebellum Virginia. J Interdiscip Hist. 2002;33(1):21-46.

Bodenhorn H. Colorism, complexion homogamy, and household wealth: some historical evidence. Am Econ Rev. 2006;96(2):256-60.

Bodenhorn H. Colourism and African-american wealth: evidence from the nineteenth-century south. J Popul Econ. 2007;20(3):599-620.

Bodenhorn H. Manumission in nineteenth-century Virginia. Cliometrica. 2011;5(2):145-64.

Crenshaw K. Demarginalizing the intersection of race and sex: a black feminist critique of antidiscrimination doctrine, feminist theory, and antiracist politics. Univ Chic Leg Forum. 1989;1:139-67.

Crenshaw K. Mapping the margins: intersectionality, identity politics, and violence against women of color. Stanford Law Rev. 1991;43(6): 1241-99.

Diette TM, Goldsmith AH, Hamilton D, Darity W Jr. Skin shade stratification and the psychological cost of unemployment: is there a gradient for black females. Rev Black Polit Econ. 2015;42(1-2):155-77.

Feliciano C. Shades of race: how phenotype and observer characteristics shape racial classification. Am Behav Sci. 2016;60(4):390-419.

Finkeldey JG, Demuth S. Race/ethnicity, perceived skin color, and the likelihood of adult arrest. Race Justice. 2019.

Goldsmith AH, Hamilton D, Darity W Jr. Shades of discrimination: skin tone and wages. Am Econ Rev. 2006;96(2):242-5.

Goldsmith AH, Hamilton D, Darity W Jr. From dark to light: skin color and wages among African-Americans. J Hum Resour. 2007;42(4): 701-38.

Green TL, Hamilton TG. Beyond black and white: color and mortality in post-reconstruction era North Carolina. Explor Econ Hist. 2013;50(1):148-59.

Gullickson A. Racial boundary formation at the Dawn of Jim crow: the determinants and effects of black/mulatto occupational differences in the United States, 1880. Am J Sociol. 2010;116(1):187-231.

Hannon L, DeFina R. Just skin deep? The impact of interviewer race on the assessment of African American respondent skin tone. Race Soc Probl. 2014;6(4):356-64.

Hannon L, DeFina R. Reliability concerns in measuring respondent skin tone by interviewer observation. Public Opin Q. 2016;80(2):534 41.

Hannon L, DeFina R, Bruch S. The relationship between skin tone and school suspension for African Americans. Race Soc Probl. 2013;5(4):281-95.

Hargrove TW. Light privilege? Skin tone stratification in health among African Americans. Sociol Race Ethn. 2018a.

Hargrove TW. BMI trajectories in adulthood: the intersection of skin color, gender, and age among African Americans. J Health Soc Behav. 2018b;59(4):501-19.

Hersch J. Skin-tone effects among African Americans: perceptions and reality. AEA Pap Proc. 2006;96(2):251-5.

Hill ME. Race of the interviewer and perception of skin color: evidence from the multi-city study of urban inequality. Am Sociol Rev. 2002a;67(1):99-108.

Hill ME. Skin color and the perception of attractiveness among African Americans: does gender make a difference? Soc Psychol Q. 2002b;65(1):77-91.

Hochschild JL, Weaver V. The Skin Color Paradox and the American Racial Order. Soc Forces. 2007;86(2):643-670.

Hunter ML. Colorstruck: skin color stratification in the lives of African American women. Sociol Inq. 1998;68(4):517-35.

Hunter ML. 'If you're light you're alright:' light skin color as social capital for women of color. Gend Soc. 2002;16(2):175-93.
Hunter M. Race, gender, and the politics of skin tone. New York: Routledge; 2005.

Hutchings V, Jefferson H, Lewis N Jr, Yadon N. The color of our skin and the content of our politics: exploring the effects of skin tone on policy preferences among african americans. Ann Arbor: University of Michigan; 2016; Unpublished manuscript.

Keith VM, Herring C. Skin tone and stratification in the black community. Am J Sociol. 1991;97(3):760-78.

Kreisman D, Rangel MA. On the blurring of the color line: wages and employment for black males of different skin tones. Rev Econ Stat. 2015;97(1):1-13.

Laidley T, Domingue B, Sinsub P, Harris KM, Conley D. New evidence of skin color bias and health outcomes using sibling difference models: a research note. Demography. 2019;56(2):753-62.

Lance H, DeFina R. The reliability of same-race and cross-race skin tone judgments. Race Soc Probl. 2020. https://doi.org/10.1007/s12552020-09282-4>

Louie P. Revisiting the cost of skin color: discrimination, mastery, and mental health among black adolescents. Soc Mental Health. 2019.

Mason PL. Not black-alone: the 2008 presidential election and racial selfidentification among African Americans. Rev Black Polit Econ. 2017:44(1-2):55-76.

Monk EP. The color of punishment: African Americans, skin tone, and the criminal justice system. Ethn Racial Stud. 2018.

Monk EP Jr. The cost of color: skin color, discrimination, and health among AfricanAmericans. Am J Sociol. 2015;121(2):396-444.

Monk EP Jr. Skin tone stratification among black Americans, 2001-2003. Soc Forces. 2014;92(4):1313-37.

Painter MA II, Holmes MD, Bateman J. Skin tone, race/ethnicity, and wealth inequality among new immigrants. Soc Forces. 2015;94(3): 1153-85.

Perreira KM, Wassink J, Harris KM. Beyond race/ethnicity: skin color, gender, and the health of youth adult in the United States. Popul Res Policy Rev. 2018.

Reece RL. What are you mixed with: the effect of multiracial identification on perceived attractiveness. Rev Black Polit Econ. 2016;43(2): 139-47.

Reece RL. Coloring weight stigma: on race, colorism, weight stigma, and the failure of additive Intersectionality. Sociol Race Ethn. 2018a.

Reece RL. Color crit: critical race theory and the history and future of colorism in the United States. J Black Stud. 2018b.

Reece RL. Genesis of U.S. colorism and skin tone stratification: slavery, freedom, and mulatto-black occupational inequality in the late 19th century. Rev Black Polit Econ. 2018c;45(1):3-21.

Robst J, VanGilder J, Coates CE, Berri DJ. Skin tone and wages: evidence from NBA free agents. J Sports Econ. 2011;12(2):143-56.

Ryabov I. How much does physical attractiveness matter for blacks? Linking skin color, physical attractiveness, and black status attainment. Race Soc Probl. 2019;11(1):68-79.

Saperstein A, Gullickson A. A 'mulatto escape hatch' in the United States? Examining evidence of racial and social mobility during the Jim Crow era. Demography. 2013;50(5):1921-42.

Sweet E, McDade TW, Kiefe CI, Kiu K. Relationships between skin color, income, and blood pressure among African Americans in the CARDIA study. Am J Public Health. 2007;97(12):2253-9.

Viglione J, Hannon L, DeFina R. The impact of light skin on prison time for black female offenders. Soc Sci J. 2011;48:250-8.

Wilkinson BC, Earle E. Taking a new perspective to latino racial attitudes: Examining the impact of skin tone on latino perceptions of commonality with whites and black. Am Politics Res. 2012;41(5):78318. https://doi.org/10.1007/s41996-020-00054-1.

Publisher's Note Springer Nature remains neutral with regard to jurisdictional claims in published maps and institutional affiliations. 